\title{
A Constraint-based Analysis of Morphological Processes in the Ibibio Language
}

\author{
Louisa Louis Michael \\ Linguistics and Nigerian Languages, University of Nigeria, Nsukka, Nigeria \\ Ndubuisi Ogbonna Ahamefula \\ Linguistics and Nigerian Languages, University of Nigeria, Nsukka, Nigeria \\ Olusanmi Olasunkanmi Babarinde \\ Linguistics and Nigerian Languages, University of Nigeria, Nsukka, Nigeria
}

\begin{abstract}
This paper is on a constraint-based analysis of morphological processes in Ibibio (Lower cross language of Niger Congo: Nigeria). The study seeks to determine the phonological processes that condition and restrict the position of an affix while specifying where an affix may appear in a string of affixes; examine the influence of a morphological form on the phonological conditions that regulates affix placement in the Ibibio language, as well as determine the constraints that account for the appropriate placement of affixes on reduplicative forms. Leaning on the optimality framework, it was revealed that nouns in Ibibio accept only vowel prefixes which provides an enabling environment for vowel processes to occur in compounding and affixation. We observed that certain phonological forms, like the productive suffix $k e$ which has differing phonological realisations depending on the structure of the verb in Ibibio, are influenced by the morphological structure of a word while others are not. Certain constraints like the intervocalic constraint, the *[CC] constraint and the harmony constraint are some of the constraints that account for full reduplication in Ibibio. Also, partial reduplication in the Ibibio language adheres to the $* \operatorname{complex}{ }^{\text {ons }}$ and the NO CODA constraint.
\end{abstract}

Index Terms - Ibibio, morphological processes, optimality theory, phonological constraints, phonotactics

\section{INTRODUCTION}

Language is a means of verbal communication among humans. Words that are used in communicating messages are formed through a number of processes. This study looks at the morphological processes in Ibibio. The analysis is couched within the framework of Optimality Theory (henceforth, OT) by Prince and Smolensky (1993) in which morphological processes are encoded in phonological constraints on the realisation of surface forms. It is primarily concerned with the phonological realisation of morphological properties and not in the nature of the morphemes themselves; its emphasis is in accounting for the influence of phonotactic restrictions on the phonological realisation of morphological processes.

The restrictions on the environment in which sounds appear are part of what defines the phonology of a language; therefore, sounds are not just combined randomly but they are combined and constrained in a well-defined pattern. Constraints are used in linguistics (in areas such as phonology, syntax and morphology) for representing properties that a linguistic phenomenon or concept must satisfy. Constraints are universal and language specific (i.e. valid for different languages). In essence, constraints stipulate properties that remove structures which are unacceptable to a language. In a constraint-based approach, the surface forms are constrained, forms not conforming to these constraints are rejected.

According to Spencer and Zwicky (2001), morphological forms when combined can affect each other phonologically but phonology has a more radical influence on morphology because it can determine whether or not some morphemes are combinable at all. As such, some morphological processes of affixation, reduplication, compounding, etc. are restricted to bases with certain phonological characteristics and cannot apply to bases without those characteristics even if they are appropriate on other grounds like (syntax, morphological and semantic).

According to Onwuka (2007), the relation of phonology and morphology lies in the area of morpho-phonology. At this point, what is considered is the phonological information necessary for morphological analysis and the morphological information necessary for phonological analysis. Therefore, a constraint-based analysis of morphological processes within the framework of optimality theory will look at mechanisms for controlling the size and contents of reduplicative morphemes (reduplication), constraints responsible for the precise placement of affixes, and constraints that account for compounding as a word-formation processes.

Many scholars have looked into the morphological processes in Ibibio but much attention has not been paid to those constraints that limit morpheme combination during word-formation processes and how such constraints determine the kind of morpheme that can occur with the other whether bound or free morpheme. This present study has not enjoyed 
much inquiry in the Ibibio language. The foregoing dearth of research in optimality account of phonological phenomena in the Ibibio language necessitates this study.

In view of the fact that languages of the world are well ordered, and not randomly distributed in deriving new words from others either through affixation, reduplication or compounding, there are constraints that limit the rules of such combinations. Therefore, this paper seeks to determine the phonological processes that condition the position of an affix and restrictions while specifying where an affix may appear in a string of affixes, examine the influence of a morphological form on the phonological conditions that regulates affix placement in Ibibio, as well as determine the constraints that account for the appropriate placement of affixes on morphological forms.

There are many aspects of grammar which reveal a great deal about morphological structures and its relation to phonology, and there are a lot more morphological processes like borrowing, calquing, etc. However, the present study will be restricted to the morphological categories expressed by affixation, compounding and reduplication. Affixation on the other hand will be restricted to prefixation and suffixation in Ibibio. Its emphasis is on accounting for the influence of phonotactic constraints and lexical exceptionality on the phonological realisation of morphological process.

The Ibibio language is one of the minority languages in Niger Delta area in Nigeria. Although it is spoken by about 4million people (Essien, 1990), it is not as widely documented as other major Nigerian languages. This work will significantly help the second language learners who may have difficulty understanding the phonotactics of the language as regards word-formation.

\section{METHODOLOGY}

The researchers collected data through elicitation using the Ibadan 400 word-list which contained nouns, verbs, adjectives adverbs, etc. Some documented materials in the Ibibio language were also consulted. The purpose was to ensure that data collected were accurate and in their standard forms. Data transcription was done using the researcher's intuitive knowledge as a native speaker

\section{THEORETICAL STUDIES}

The theory of constraint and repair strategies (henceforth, TCRS) is a constraint-based theory propounded by Paradis in 1987. A repair strategy as opposed to a rule-based theory is an operation that applies to a phonological unit or a structure in order to repair the violation of structural or segmental phonological constraint of a universal language or a particular type of language. This repair can take various forms, for example insertion, deletion or modification of linguistic material (Murphy, 2018).

Declarative phonology is a constraint-based theory propounded by James Scobbie 1993. According to him, declarative phonology (henceforth, DP) provides a radical solution to the interaction problem of constraints. Firstly, in DP all elements of the phonology are constraints, so one only has to characterise constraint interaction but not the interaction of constraints with any other type of element such as the lexicon or rule set. Unlike the TCRS, DP cannot make repairs because this would mean adding or subtracting information from the pool at a point or another, neither can constraints truly conflict, as this would render the constraint pool incoherent. However, in DP, violations are avoided or pre-empted as there is no repair in DP, since that would mean removing a constraint from the constraint pool.

Optimality theory was originally proposed by linguist Allan Prince and Paul Smolensky in 1993 and later expanded by John J. Mccarthy and Prince later in 1993. Although much of the interest in optimality theory has been associated with its use in phonology, the area to which it was first applied, the theory is also applicable to other subfield of linguistics, like syntax and semantics. Optimality theory as a linguistic model proposes that the observed form of a language arises from the interaction between conflicting constraints. In OT, candidates are compared by a hierarchy of violable constraints. The constraint assesses the form of each candidate, how it relates to the input and perhaps other properties. Candidates usually differ in performance on various constraints as such of the two or more candidates, the more harmonic is that which performs better on the highest-ranking constraint that distinguishes between them. Elements of OT include constraints (con); generator (gen) and evaluator (eval).

Generator: (gen, also known as the candidate set) is a mechanism which relates the input to a set of candidate representation. Gen takes an input, and manipulates the input to generate randomly the list of possible outputs or candidates.

Constraints: Constraint according to Kager (1999:5) can be defined as "a structural requirement which satisfies constraints if it fully meets the necessary structural requirements". Constraint provides the criteria in the form of strictly ordered violable constraints used to decide between candidates.

Evaluator: Evaluator on the other hand selects the optimal candidate from a set of candidates created by generator. It chooses the optimal candidate based on constraints and this candidate is the output.

\section{EMPIRICAL STUDIES}

Akinlabi and Urua (2000) worked on tone in Ibibio verbal reduplication. The aim of the study was to describe the tonal patterns observed in prefixing reduplication in Ibibio verb, specifically prefixing reduplication in three constructions: the imperative contrastive, the declarative contrastive and the perfective. The optimality theory was used 
as the theoretical framework. The researchers provided evidence for the full model of reduplicative identity and fixed segments which results from the realization of a tonal morpheme. According to the researchers, Ibibio is a two-tones plus down-step language. The researchers claim that tone is no different from other aspects of the signal when it comes to reduplicative transfer and this was demonstrated using the correspondence constraint of OT. The researchers in spite of assumptions that tone reduplicates with segments, were of the view that faithful transfer of tone must be independent of faithful transfer of segments. The similarity between the study reviewed and the current study lies in their collective effort to study constraints on reduplicative morphemes in Ibibio. However, they differ in their point of focus. While Akinlabi and Urua (2000) focused on constraints on the tonal tier which according to the researchers, is independent of the segmental tier; the current study looks at constraints on reduplicative morphemes at the segmental level.

Mbah (2006) worked on reduplication in Ibibio: an optimality account. The paper studied reduplication in Ibibio, using the correspondence model of the optimality theory. The study investigated how some phonological conditions evident in the language use relevant constraints to achieve their results. The researcher stated that two types of reduplication exist in Ibibio, and these include the complete and partial reduplication which affects only the first CV of the base. According to the researcher, in complete reduplication, elements in the base are wholly copied by the reduplicant, and reduplicants forbid consonant clusters. The study discovered that in places where there are consonant clusters, vowels are inserted between the base and the reduplicant to avoid such clusters. The researcher went on to state that complete reduplication in Ibibio results when a universal constraint $\mathrm{MAX}_{\mathrm{BR}}$ is not dominated. However, if $\mathrm{MAX}_{\mathrm{BR}}$ becomes highly dominated, it will result in the emergence of the unmarked segment (TETU), which manifests when some phonological constraints block exact copying of the base by the reduplicant. The similarity between the study reviewed and the current study lies in their collective effort to study constraints on reduplicative morphemes in Ibibio. However, they differ in their scope. While the current study covers a wider scope by looking into constraints on other morphological processes, Mbah (2006) payed attention to reduplication alone.

Mba (2017) worked on hiatus resolution in Igbo. Mba states that the study of hiatus as a concept shows that many languages of the world do not prefer hiatus, some completely avoid it while some devise strategies for resolving it. According to the researcher, hiatus is a phenomenon where two different vowels occurring in a juxtaposition without an intervening consonant have different repair strategies which include vowel assimilation and vowel deletion. The theoretical framework adopted is the optimality theory by Prince and Smolensky. The study according to the researcher seeks to establish the occurrence of hiatus in Igbo as well as identify the hiatus resolution strategies applicable in the language. Finally, Mba (2017) posits that Igbo does not permit hiatus and uses the assimilation and deletion method as strategies for resolving the non-preferred configuration. The study reviewed and the current study differs in their phonological area of study. While the current study looks at constraints on morphological processes, the study reviewed looked at the resolution of hiatus in the Igbo language. However, both studies adopt the optimality theory as a framework for data analysis.

\section{THEORETICAL FRAMEWORK}

Of the above theories of phonological constraints, Scobbie (1993) states that the TCRS is similar to optimality theory in that it makes crucial use of forms which violate surface constraints but it also differs with the optimality theory in that such forms exist only at abstract intermediate levels. As such constraint violations are always repaired. Deletion is a possible repair strategy, therefore, TCRS is procedural as compared to declarative phonology which is non-procedural. Therefore, when two constraints are violated by a single form in TCRS, two repairs might apply giving different results. However, since the optimality theory allows one to generate language-specific constraints, and constraints can as well be violated to bring out the optimal candidate, we find it a more comprehensive, and adequate framework for this study.

\section{DATA PRESENTATION}

This section intends to explain the constraints and phonological conditions that regulate such morphological processes as compounding, reduplication and affixation in Ibibio.

\section{A. Compounding in Ibibio}

Ibibio compound words are a combination of two content words. According to Urua (1998) compounds in Ibibio may be classified into two parts: those that have a direct composition of two or more nouns, and those which are derived through verbs. Unlike in English, where different word classes can be utilized in compounding process, compounds in Ibibio are generally nominal-based (Urua, 1998).

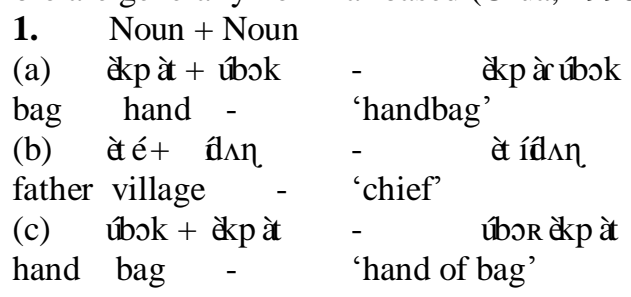




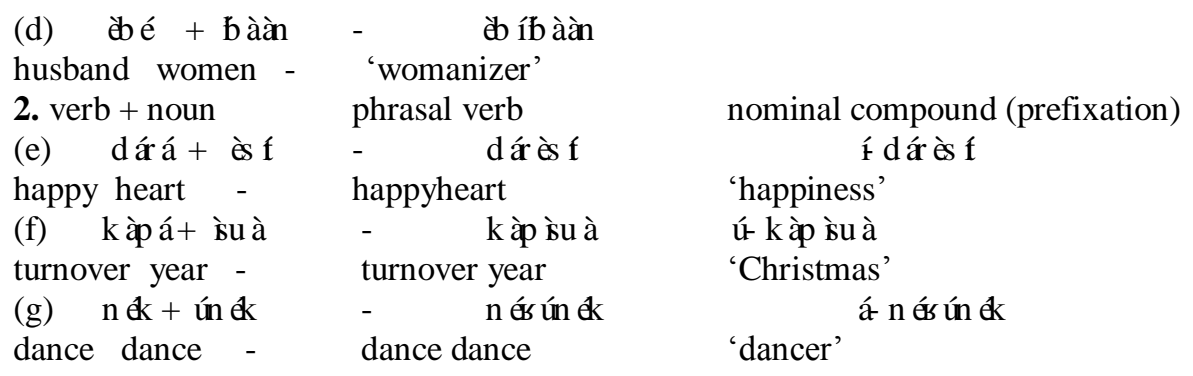

\section{B. Reduplication in Ibibio}

Ibibio has the complete and partial reduplication. Certain word classes in Ibibio may be derived through the complete reduplication process. Such word classes include: adjectives from nouns, adjectives from adjective, nouns from verbs, adverbs from nouns and adverbs from adjectives (Urua, 1998). Complete reduplication in Ibibio is productively derived by faithfully repeating the base. The consonants, vowels and tones of the base are completely copied by the reduplicant. In the derived form, one half is the base while the other half is the reduplicant (Mbah, 2006). Partial reduplication in Ibibio comes in form of a prefix and it involves attaching the repeated part of the word to the base.

From the data below, it is observed that complete reduplication in Ibibio is derived by fully repeating the base. The consonants, vowels and tones are copied by the reduplicant. The new or derived form consists of two parts known as the base and the reduplicant. The identity of the base and the reduplicant is ensured by a set of the base-reduplicant and input-output faithfulness constraints, where faithfulness constraints outrank markedness constraints.

3. Data showing reduplication in Ibibio
(a) èkpàt 'bag'
(b) ìbok 'medcine'
ìbonìbok 'medicinal'
ǹdòmǹdòm 'clayey'
'bogus'
(c) ǹdòm 'clay'
(d) keed 'one'
keerekeed 'one each

4. data showing Partial reduplication

(e) dép 'buy' de.dep (be buying)

(f) nèk 'dance' nè.nèk (be dancing)

(g) tuuk 'touch' tó.túúk (be touching)

(h) kippé 'pluck' kè. kippé (be plucking)

(i) frán 'fry' fà.frán (be frying)

\section{Affixation in Ibibio}

Josiah and Udoudom (2017) observes that most grammatical properties in Ibibio are indicated through the prefixation process. Essien (1990) states that in Ibibio inflectional morphemes are characterised by prefixes while derivational morphemes are typically suffixes. One major feature of the Ibibio language is that it is an agglutinative language. That is, it is capable of forming new words by taking other words or affixes without changing the form of the root.

\section{a. Data showing prefixation in 1 bibio}

Nouns formation in Ibibio through prefixation.
5. Verb
(a) tó - 'plant'
(b) má- 'love'
Noun
é-tó 'plant'

6. Plural formation in Ibibio through prefixation (mmè- morpheme)
(a) áwó- 'person'
(b) ùsán- 'plates'
mměwó 'many people
mmùsán 'plates'

7. Data showing vowel assimilation in Ibibio through prefixation

(a) sé + ówò sééwó

look + person

(b) kpé + íkpé

judge + case

'look at someone'
kpííkpé
'judge a case'

\section{b. Suffixation in Ibibio}

Suffixation is a very productive derivational process in Ibibio is well constrained phenomena. The $-k e$ morpheme which appears to be the most productive suffix in Ibibio has different melodic realizations which is dependent on the structure of the verb.

Data showing suffixation in Ibibio

\section{Reflexive suffix in Ibibio}
8. (a) dip 'hide'
(b) $\sin$ 'put'
dip + é $\rightarrow$ dißé $\quad$ 'hide onself'
$\sin +$ é $\rightarrow$ siné 'dress oneself'

Reversive suffix

9. This deals with oppositeness of certain verb forms 
(a) f $\mathrm{k}$ 'cover

$\mathrm{f} \Lambda \mathrm{k}+\mathrm{k}$ э 'uncover'

(b) tèm 'cook' tèm + mè 'remove cooking from fire'

Negation in Ibibio through suffixation

In Ibibio, the suffix $-k e$ is used to mark negation in a CV, CVC and CVC (C) V verb structure. However, it has different melodic realization depending on the structure of the verb.

10.

CV

(a) Sé 'look' sé + ké $\rightarrow$ sésé 'not looking'

CVC

(b) dép 'buy'

dép + pé $\rightarrow$ déppé $\quad$ 'not buying'

CVCV

(c) Kéré 'thing'

kéré + ké $\rightarrow$ kéréké $\quad$ 'not thinking'

\section{DATA ANALYSIS}

\section{A. Optimality Account of Compounding in Ibibio}

From the data in (a), (c) and (g) above, it can be observed that consonant weakening is a phonological process found in the Ibibio language and this occurs when a consonant sound occurs in-between two vowel sounds at morpheme or word boundary (intervocalic environment). The voiceless plosive $/ \mathrm{k} /$ in an intervocalic environment will become either / $/$ or $/ \mathrm{R} /$ depending on the $[ \pm$ backness] of the preceding vowel sound. The leading constraints will account for intervocalic weakening in Ibibio.

The asterisk $(*)$ denotes that a structure is unacceptable.

License [voice]\#: intervocalic weakening or voicing at morpheme or word boundary

[+ back + syll] [R]\#: feature of [+cons] following a back vowel at word/morpheme boundary.

[-back +syll] [в]\#: feature of [+cons] following a front vowel at morpheme or word boundary.

Dep -IO every segment in the output must have a corresponding segment in the input (no insertion)

Constraints are arranged across the top of the tableau in a hierarchy of decreasing importance from left to right. Also, shading shows constraints that are immaterial to the selection of the optimal candidate (especially those below a constraint for which a fatal violation is incurred).

1. Consonantal weakening in intervocalic position

TABLEAU 1

tuak+ ukot 'palmwine tapper'

\begin{tabular}{|c|c|c|c|c|}
\hline tuak + ukot -UR & License (voice) & [+back +syll] [R] & [-back +syll] [в] & Dep-io \\
\hline a. tuakukot & $* !$ & $*$ & & \\
\hline b.tuasukok & & $* !$ & & $*$ \\
\hline c.tuarukot & & & $*$ & $*$ \\
\hline
\end{tabular}

Here, it is observed from tableau 1 above that the ranking of constraints leads to the selection of a candidate other than that which most closely matches the input. This indicates that the markedness constraint outranks the faithfulness constraints. Candidate (a) incurs a fatal violation of the highest ranked constraint License (voice) as such as been ruled out. Candidate (b) and candidate (d) do not violate the highest ranked constraint but candidate (c) tuarukst performs better because it incurs the least violation and as such becomes the optimal candidate

TABLEAU 2

nek + unek 'dance'

\begin{tabular}{|l|l|l|l|l|}
\hline nek + unek - UR & License (voice) & {$[$-back + syll $][$ в $]$} & {$[+$ back +syll] [R] } & dep-IO \\
\hline b. nerunek & & & $*$ & $*$ \\
\hline c. nekunek & & $*$ & & $*$ \\
\hline d. nerunek & $* !$ & $* !$ & $*$ & $*$ \\
\hline
\end{tabular}

From tableau 2 above, it is observed that the markedness constraint License (voice) is ranked above the faithfulness constraint. It is also ranked above the [+back +syll] [ $\mathrm{b}]$ constraint. This is because the constraint License (voice) prohibits the occurrence of oral stops in an intervocalic environment while the [-back +syll] [ь] determines what feature the consonant sound takes in an intervocalic environment based on the backness or frontness of the preceeding vowel sound. As such, candidate (a) emerges the optimal candidate because it satisfies the two highly ranked constraints.

\section{Vowel deletion in compounding}

In Ibibio, wherever two vowels occur in juxtaposition at word boundary, one of the vowels is deleted. Here, the vowel height constraint comes into consideration. This constraint states that where there is a - high and + high vowel 
occurring in juxtaposition, the -high vowel should be deleted. As seen in data (e) and (f) above. The following constraints suffice for an OT analysis

No hiatus: Two adjacent vowels cannot be associated to different features (deletion of a low vowel in juxtaposition with a high vowel).

Max-IO: Every segment in the input has a correspondent in the output (no deletion)

Dep-IO: Every segment in the output should have a corresponding segment in the input (no insertion).

TABLEAU 3

ukapa +isua 'christmas'

\begin{tabular}{|l|l|l|l|}
\hline ukapa + isua - UR & $*[-$ high +syll] [+high +syll] & Dep [+high] & Max [-high] \\
\hline b.ukapapisua & & & $*$ \\
\hline c.ukapaisua & & $*$ & $*$ \\
\hline d.ukapasua & $* !$ & & \\
\hline
\end{tabular}

In tableau 3 above, candidate (c) and candidate (d) are ruled out because the incur fatal violation on the highest ranked constraint as such cannot emerge winner. Candidate (a) therefore is the optimal candidate because it satisfies a highly ranked constraint and only violates a low-ranking constraint.

\section{Constraint showing vowel assimilation in compound words.}

According to Urua (2007), assimilation rather than deletion occurs when adjacent vowels bear non-identical tones. But in noun plus noun construction, complete vowel assimilation takes place even in the midst of identical tones. Example as seen in data (b) and (d). The leading constraints are generated for an OT analysis

No hiatus: Two adjacent vowels cannot be associated to different features (assimilation to a following high vowel)

Max-IO: Every segment in the input has a correspondent in the output (no deletion)

Dep-IO: Every segment in the output should have a corresponding segment in the input (no insertion).

TABLEAU 4

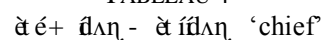

\begin{tabular}{|l|l|l|l|}
\hline èté + íd $\Lambda \eta$ - UR & No Hiatus & Max-IO & Dep-IO \\
\hline a. eteid $\Lambda \eta$ & $* !$ & & \\
\hline b.etiid $\Lambda \eta$ & & $*$ & $*$ \\
\hline c.eteed $\Lambda \eta$ & $*$ & $*$ & $*$ \\
\hline d.etid $\Lambda \eta$ & & $*$ & \\
\hline
\end{tabular}

In tableau 4 above, it is observed that a markedness constraint is ranked above faithfulness constraints. This is because the structural well-formedness of an output ranks above its correspondence to the input. In Ibibio, the "No Hiatus constraint" can be resolved through assimilation process but, the vowel segment $\mathrm{V}_{1}$ must assimilate to the following high vowel. In the analysis above, candidate (a) is ruled out because it incurs a fatal violation of a highly ranked constraint. Candidate (c) violates the high-ranking constraint by assimilating to the preceding mid vowel /e/ instead of the following high vowel /i/. Therefore, candidate (b) emerges the optimal candidate.

TABLEAU 5

èbé + íbààn - èbííbààn

\begin{tabular}{|l|l|l|l|}
\hline èbé + Íbààn & No Hiatus & Max-IO & Dep-IO \\
\hline a.ebeiban & $* !$ & $*$ & \\
\hline b.ebibaan & & $*$ & \\
\hline racebiibaan & & $*$ & $*$ \\
\hline d.ebiebaan & $* !$ & & \\
\hline
\end{tabular}

Here, candidate (c) is the optimal candidate because it satisfies the highly ranked constraint and aligns with the phonotactic constraints of the language.

\section{B. Optimality Account of Reduplication in Ibibio}

From the data in (3) above, it is observed that complete reduplication in Ibibio is derived by fully repeating the base. The consonants, vowels and tones are copied by the reduplicant. The new or derived form consists of two parts known as the base and the reduplicant. The identity of the base and the reduplicant is ensured by a set of the base-reduplicant and input-output faithfulness constraints, where faithfulness constraints outrank markedness constraints. Constraints necessary for the analysis are:

Max-IO: every segment S1 has a correspondent in S2

Dep-IR: every segment of the reduplicant has a correspondent in the input.

Ident BR: place specifications in the reduplicant are the same as place specifications in the base

$* \mathrm{Vc \# V}$ : No intervocalic stop at word boundary.

*C\#C: No consonant cluster at morpheme or word boundary.

$* \mathrm{Vc \# V}$ : No intervocalic stop at word boundary. 
TABLEAU 6 SHOWING FULL REDUPLICATION IN IBIBIO ekpat-ekpat 'baggy'

\begin{tabular}{|l|l|l|l|l|}
\hline Red-ekpat & Max-IO & DEP-IR & *VC\#V & Ident BR (place) \\
\hline r. ekpar-ekpat & & & & \\
\hline b.ekpat-ekpar & $* !$ & & & \\
\hline c. ekpaR-eakpat & $* !$ & $*$ & & $*$ \\
\hline d. ekpat-ekpat & & & $* !$ & \\
\hline
\end{tabular}

Here, candidate (a) is the optimal candidate while candidate (c) is the worst of all the candidates. It violates all constraints except $* \mathrm{VC} \# \mathrm{~V}$. It violates Max-IO because of the presence of the uvular trill /R/ in the reduplicant, which does not correspond to the base. It violates Ident-BR (place) because /R/ is an uvular sound while /t/ is an alveolar sound, as such do not agree in place. Candidate (a) is optimal because it satisfies all high-ranking constraints.

TABLEAU 7

Keed + keed 'one each'

\begin{tabular}{|l|l|l|l|l|}
\hline Red + keed & Max-IO & *C\#C & $*$ VC\#V & Dep IR \\
\hline b. kee keed & & & & $*$ \\
\hline c. keedkeed & $* !$ & & $*$ & \\
\hline
\end{tabular}

In tableau 7 above, candidate (a) emerges the optimal candidate having violated a low ranked constraint. Candidate (C) has violated only one constraint which is *CC (no consonant cluster at word boundary) but it cannot become the optimal candidate because it incurs a fatal violation on highly ranked markedness constraints.

1. Partial reduplication

Partial reduplication in Ibibio repeats only the first $\mathrm{CV}$ of the base. However, there are modifications in certain instances. The following constraints will suffice for partial reduplication in Ibibio

Max-IO = Every segment in the input must have a correspondent in the output (no deletion)

No CODA = No coda in the reduplicant

*Complex ${ }^{\text {ONS }}$ : No complex onset in the reduplicant

Align ( R prefix L): The left edge of the prefix must align with the right edge of the base word.

Max-BR: every segment in the base must have a correspondent in the reduplicant.

In Ibibio, the well-formedness constraint NO CODA must be ranked higher than the MAX-BR so as to result in partial reduplication.

TABLEAU 8

Fran $\rightarrow$ fa-fran 'be frying'

\begin{tabular}{|l|l|l|l|l|}
\hline Red- fran & No CODA & ${ }^{*}$ Complex ${ }^{\text {ons }}$ & Align (R prefix L) & Max-BR \\
\hline a. fra-fran & & $* !$ & & \\
\hline b. fa-fran & & $*$ & & $*$ \\
\hline c. fran-fran & $* !$ & & & \\
& & & $*$ & $*$ \\
\hline d. ra-fran & & $*$ & & \\
\hline
\end{tabular}

Here, candidate (b) being the optimal candidate violates only the Max-BR constraint. Candidate (c) is ruled out because it violates *complex ons and the No Coda constraint. In Ibibio, codas are allowed in the base but not in the prefixal reduplicant. Also, complex ${ }^{\text {ons }}$ is allowed at the base but not in the reduplicant.

\section{Affixation in Ibibio}

\section{Optimality account of prefixation Ibibio}

In Ibibio, prefixation is productive and gives rise to inflections as well as derivations. However, there are certain constraints that account for prefixation in Ibibio. Therefore, the following constraints will suffice for an OT analysis of prefixation in Ibibio.

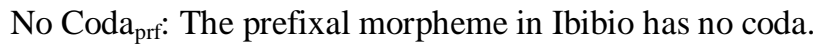

$*[-$ high + syll]\# [+high + syll]: delete low vowel at morpheme or word boundary where there is a following high vowel.

No Hiatus: Two adjacent segments cannot be associated with different features.

Max-IO: Every segment in the input has a correspondent in the output (No deletion)

Dep-IO: Every segment in the output has a correspondent in the input (No insertion).

TABLEAU 9 THE PLURAL MORPHEME 'MME'

Mme + usan $\rightarrow$ mmusan 'plates'

\begin{tabular}{|l|l|l|l|l|}
\hline Mme+usan & No hiatus & $*[-$ high + syll]\# [+high + syll] & No coda & Max-IO \\
\hline a. mmesan & & $* !$ & & \\
\hline b. mmeusan & $* !$ & & & \\
\hline c. mmusan & & & $*$ & $*$ \\
\hline d. mmsan & & & $*$ & $*$ \\
\hline
\end{tabular}


From tableau 9 above, it is observed that the height constraint which states that a [-high] vowel should be deleted when there is a following [+high] at morpheme or word boundary. This constraint ranks higher than the Max-IO constraint. Candidate (a) and candidate (b) violates the highest ranked constraint but candidate (c) which violates the least ranked constraint (max-IO) emerges the optimal candidate.

TABLEAU 10 TABLEAU SHOWING VOWEL ASSIMILATION THROUGH PREFIXATON IN IBIBIO

\begin{tabular}{|c|c|c|c|c|}
\hline \multicolumn{5}{|c|}{ Se+owo $\rightarrow$ seewo 'look at someone' } \\
\hline $\mathrm{Se}+$ owo & No hiatus & No coda & Max-IO & Dep-IO \\
\hline a. sek+owo & & $* !$ & & $*$ \\
\hline b. seowo & $* !$ & & & \\
\hline c. seewo & & & & $*$ \\
\hline d. sen+owo & & $*$ & * & * \\
\hline
\end{tabular}

Candidate (d) has been ruled out because it violates the "No coda" constraint which is a high-ranking constraint in Ibibio prefixation. Candidate (a) and (b) have also been ruled out because they violate the No coda and No hiatus constraints respectively. In Ibibio, the prefixal morpheme can only be an open CV or a CCV structure. Closed syllable structures such CVC is not allowed as a prefix in Ibibio. Therefore, candidate (c) emerges as the winning candidate.

\section{Optimality account of suffixation in Ibibio}

Suffixation is a well constrained phenomena in Ibibio. The -ke morpheme which appears to be the most productive suffix in Ibibio has different melodic realizations which is dependent on the structure of the verb (Urua, 2007). The following constraints will suffice for suffixations in Ibibio.

Harmony: vowel in the suffix must harmonise with vowel in the root.

License [voice]\#: intervocalic weakening or voicing at morpheme or word boundary

Align (stem R suffix L): The right edge of the stem must correspond to the left edge of the suffix.

*[high, central]: high or central vowel is not allowed as suffix.

$*(\mathrm{CvC})$ No insertion of vowel between two identical consonant sounds.

Dep-IO: Every segment in the output must have a corresponding segment on the input (no insertion)

TABLEAU 11

$\operatorname{dip}+\mathrm{pi} \rightarrow$ dippe 'not hiding'

\begin{tabular}{|l|l|l|l|l|}
\hline Dip + pi & Align (stem R suffix L) & $*[$ high, central] & Harmony & Dep-IO \\
\hline b. dip-pe & & & $*$ & $*$ \\
\hline c. dip-ki & $* !$ & & & \\
\hline d. di $\beta-e$ & $* !$ & $* !$ & & $*$ \\
\hline
\end{tabular}

In tableau 11, candidate (a) emerges the optional candidate. It satisfies the two high-ranking markedness constraints. It is observed that in the output form, the suffix uses the mid- front vowel /e/, this is because high or central vowels $/ i, \dot{i}$, $\mathrm{u}, \Lambda /$ are not permitted suffixes in Ibibio.

TABLEAU 12

nam $+\mathrm{ke} \rightarrow$ namma 'not doing'

\begin{tabular}{|c|c|c|c|c|}
\hline nam+ke - UR & Harmony & Align (stem R, suffix L) & $*[\mathrm{CvC}] \#$ & Dep-IO \\
\hline a. nam-ma & & & & $*$ \\
\hline b. nam-ke & $* !$ & $* !$ & & \\
\hline c. nam-ama & & & $* !$ & $*$ \\
\hline d. nam-ka & & $* !$ & & $*$ \\
\hline
\end{tabular}

From the table, it is observed that the /-ke/ suffix which marks negation harmonises with the last consonant of the verb stem which is a CVC structure. The [+back] vowel also harmonises with the vowel of the root word which is a constraint in the Ibibio language. Candidate (b) which copies exact features of the underlying representation violates the Harmony and Alignment constraint. Candidate (c) is ruled out because at violates the *[cvc]\# constraint which permits identical consonant sounds at word final position. Therefore, candidate (a) emerges the winner.

\section{SUMMARY OF FINDINGS AND CONCLUSION}

This study examines a constraint-based analysis of the connection between phonology and morphology in the Ibibio language and shows the effect of phonology on morphology. Findings reveal that in the Ibibio language, the placement of affixes in a reduplicative form are well constrained, this implies that reduplicants are not randomly affixed to the base. Reduplicants in the Ibibio language are affixed to the left, as such occur as prefixes. In full reduplication, elements are completely copied by reduplicant. Certain constraints like the intervocalic constraint which prohibits the occurrence of intervocalic stops, the $*[\mathrm{CC}]$ constraint which requires that an epenthetic vowel be introduced to break consonant clusters and the harmony constraint which requires that such vowel must harmonise with the vowel of the basereduplicant, are some of the constraints that account for full reduplication in the Ibibio language. Also, partial 
reduplication in the Ibibio language adheres to the $*$ complex ${ }^{\text {ons }}$ and the NO CODA constraint. These constraints prohibit codas and complex onsets in the reduplicant, even though it is permitted in the base.

The study observes that nouns in the Ibibio language accept only vowel prefixes, therefore, it provides an enabling environment for vowel processes to occur in compounding and affixation. Some of the phonological processes that condition word formation processes in Ibibio include: vowel assimilation, vowel insertion, intervocalic weakening, vowel harmony, etc. The study also observes that certain phonological effects are influenced by the morphological structure of a word while others are not. For instance, the productive suffix $-k e$ has differing phonological realisations depending on the structure of the verb.

In conclusion, the study confirms that word formation processes in Ibibio are well patterned and not randomly distributed. In the study, it was observed that compounding, reduplication and affixation cut across phonology, morphology interface. Morphologically, they are processes for language enrichment, where new words are produced from existing ones. Phonologically, compounding, reduplication and affixation are regulated by certain phonological conditions which have to comply to with the phonotactic constraints of the Ibibio language. In this work, we also observed that phonological conditions used to realise morphological constructions are essentially the same for compounding, reduplication and affixation in Ibibio.

\section{REFERENCES}

[1] Akinlabi, Akinbiyi. \& Urua, Eno-Abasi. (2000). Tone in Ibibio verbal reduplication. In H. E. Wolff \& O. Gensler (eds.), Proceedings of the 2nd World Conference of African Linguistics Leipzig 1997, 279-291. Koln: Rudtger koppe.

[2] Essien, Okon. (1990). A grammar of the Ibibio language. Ibadan: University Press

[3] Josiah, Udoma \& Udoudom, John. (2017). Morphophonemic analysis of inflectional morphemes in English and Ibibio nouns: implications for linguistic studies. Journal of Education and Learning, 1(2). 72-81.

[4] Kager, René. (1999). Optimality theory. Cambridge: Cambridge University Press.

[5] McCarthy, John. \& Prince, Allan. (1993). Prosodic morphology: Constraint interaction and satisfaction. New Brunswick: NJ.

[6] Mbah, Evelyn. (2006). Reduplication in Ibibio: An optimality account. Journal of the Linguistics Association of Nigeria, 9. 2138.

[7] Mba, Oluchi. (2017). Hiatus resolution in Igbo. MA dissertation, University of Nigeria, Nsukka.

[8] Murphy, Andrew. (2018). Resolving conflicts with violable constraints: On the cross modular parallelism of repairs. https://andrew.murphy.leipzig/2018. Retrieved on March 2, 2018.

[9] Onwuka, Sandra. (2007). The interface of morphology and phonology in Achalla dialect of Igbo. MA dissertation, University of Nigeria.

[10] Paradis, Carole. (1987). Explanation for constraints violation. Paper Presented at the MIT Colloquia, December, $3^{\text {rd }}$. MIT, Cambridge.

[11] Prince, Allan. \& Smolensky, Paul. (1993). Optimality theory. New Brunswick, Colorado: Boulder.

[12] Scobbie, James. (1993). Constraint violation and conflict from the perspective of declarative phonology. Canadian Journal of Linguistics, 4(1), 55-67.

[13] Spencer, Andrew. \& Zwicky, Arnold. (2001). The handbook of morphology. Oxford: Wiley Blackwell.

[14] Urua, Eno-Abasi. (1998). Aspects of Ibibio phonology and morphology. PhD Thesis, University of Ibadan, Ibadan.

[15] Urua, Eno-Abasi. (2007). Ibibio phonetics and phonology ( $2^{\text {nd }}$ edition). Port Harcourt: M\&J Grand Orbit Communications Ltd.

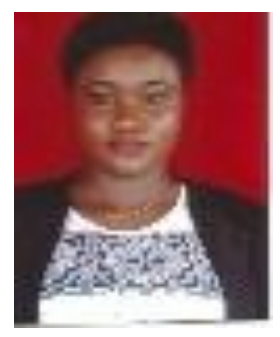

Louisa Louis Michael was born in Etinan, Akwa Ibom State on $15^{\text {th }}$ August, 1993. She had her Bachelor of Arts Degree in Linguistics in 2015 at the University of Uyo and Master of Arts in Linguistics in 2019 at the University of Nigeria, Nsukka. Louisa is currently a doctoral student in Linguistics at the University of Nigeria, Nsukka. Her speciality in phonetics and phonology.

She has a publication entitled, "Effectiveness and limitations of computer-based therapy in managing language" published in Journal of Language and Linguistics, 9 (2), 184-215.

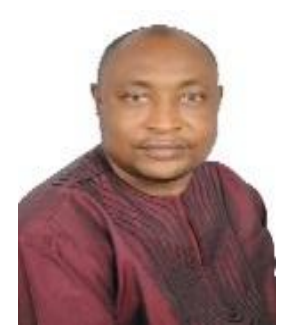

Ndubuisi Ogbonna Ahamefula was born Umuahia, Abia State on 12 March, 1973. He had his Bachelor of Arts Degree and Master of Arts Degree in Linguistics at the University of Nigeria, Nsukka. Ndubuisi is a doctoral student in the same University. He specializes in applied linguistics and sociolinguistics.

He has a number of publications to his credit including, Contrastive Analysis of consonantal phonemes and Phonotactics of Igbo and Ijo (Izon)". Journal of Linguistic Association of Nigeria (JOLAN), 21(2), 206-223. The Igbo Language Need Analysis of Non-Igbo in the University of Nigeria Postgraduate Students: Implication for Curriculum. Research on Humanities and Social Sciences. Vol.3(14), 57-68.

Mr. Ahamefula is a member of Linguistic Association of Nigeria. 


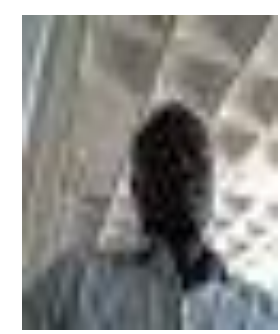

Olusanmi Olasunkanmi Babarinde was born in Gbongan Osun State on $22^{\text {nd }}$ May, 1974. He had his Bachelor of Arts Degree at the University of Ilorin. He obtained M.A and PhD degrees in Linguistics at the University of Nigeria in 2006 and 2012 respectively. His area of specialization is phonology, morphology, and language documentation. He is a postdoctoral student in the Department of Linguistics and Nigerian Languages, University of Nigeria Nsukka.

Computer-assisted language instruction and language learning: Evidence from the English-learning Yoruba talking books 1-5. Language Matters: Studies in the Languages of Africa. 50(2), 100-111. Theme, diction and prosodic systems in Yoruba lullabies. International Research in Children's Literature, 12(1). 1833

His professional associations include Linguistic Association of Nigeria, Association for the Promotion of Yoruba Language and Culture, and Modern Language Association of Nigeria. Computer-assisted language instruction and language learning: Evidence from the English-learning Yoruba talking books 1-5. Language Matters: Studies in the Languages of Africa. 50(2), 100-111. Theme, diction and prosodic systems in Yoruba lullabies. International Research in Children's Literature, 12(1). 18-33. 